\title{
Orthodontic Intrusion Using Temporary Anchorage Devices Compared to Other Orthodontic Intrusion Methods: A Systematic Review
}

This article was published in the following Dove Press journal:

Clinical, Cosmetic and Investigational Dentistry

\author{
Basma AIMaghlouth' \\ Aqilah AIMubarak' \\ Ibrahim Almaghlouth ${ }^{2}$ \\ Reem AlKhalifah ${ }^{3}$ \\ Amal Alsadah ${ }^{4}$ \\ Ali Hassan ${ }^{5}$ \\ 'Orthodontic Department, Dammam \\ Medical Complex, Dammam, Saudi \\ Arabia; ${ }^{2}$ Department of Medicine, \\ College of Medicine, King Saud \\ University, Riyadh, Saudi Arabia; \\ ${ }^{3}$ Pediatric Endocrinology, College of \\ Medicine, King Saud University, Riyadh, \\ Saudi Arabia; ${ }^{4}$ Dental Department, \\ Ministry of Health, Hafr Al Batin, Saudi \\ Arabia; ${ }^{5}$ Department of Orthodontics, \\ School of Dentistry, King Abdulaziz \\ University, Jeddah, Saudi Arabia
}

Objective: To systemically review all clinical trials that evaluate the effectiveness of orthodontic intrusion using bone anchorage devices versus using other orthodontic techniques in adult patients. Material and Methods: All randomized, controlled clinical trials and prospective studies that compare the use of TADs in intrusion versus alternative devices from the year 2000 to 2019 were searched using various electronic databases. Databases used include Pubmed, Cochrane, Scopus, Lilacs, and ScienceDirect. Selection was initially made by reading the titles and abstracts of potential suitable studies. The final selection was made after reading the full retrieved articles. A methodological score developed by Lagravère was used to assess the quality of evidence. The selection process was illustrated using a PRISMA flow chart.

Results: A total of 3942 articles were retrieved, from which only two randomized clinical trials met the inclusion criteria. This presented a low to medium level of evidence to support the hypothesis that TADs are more effective than other orthodontic intrusion techniques for intruding upper incisors and improving upper incisor to lip relation while eliminating the adverse effect of compromising vertical posterior anchorage. Shorter treatment times and less root resorption were found in the TAD group.

Conclusion: There is insufficient evidence to state that TADs can be used as orthodontic anchorage to effectively intrude the incisors without the need for patient cooperation. Future high quality prospective randomized clinical trials are required.

Keywords: orthodontic intrusion, temporary anchorage devices, mini-implants, mini-screw

\section{Introduction}

Intrusion is considered one of the most difficult tooth movements to apply due to lack of available anchorage, the need for patient cooperation, and unpredictable retention results. ${ }^{1}$ Many orthodontic methods are available to produce intrusion, including J-hook headgear, utility arches, 3-piece intrusion arches, or reverse curved arches. The adverse effect of using these methods is usually an extrusive movement of the posterior teeth and labial tipping of the anterior teeth. ${ }^{2}$

Recently, the use of temporary anchorage devices (TAD), which are stainless steel or an alloy of titanium placed into the buccal or palatal alveolar bone, ${ }^{3}$ has been popular for intrusion of teeth and there are many reports support that TADs is superior than other orthodontic methods of intrusion. However, the evidence is not clear yet.

Correspondence: Ali Hassan

Email aakbr@kau.edu.sa 
The null hypothesis of the study that there is no significant differences in the effectiveness of intrusion using temporary anchorage devices (TADs) and other orthodontic techniques.

The purpose of this study was to compare the skeletal and dental changes in subjects treated with different anchorage systems with the same orthodontic mechanics and to evaluate which anchorage system is better suited for vertical anchorage.

\section{Materials and Methods}

\section{Population} Inclusion Criteria

-Studies design: Randomized clinical trials (RCTs) and Cohort studies only.

-Studies that compare the effect of miniscrew in orthodontic intrusion versus other intrusion techniques.

-Human studies using adult male and female participants (18 years of age or older), receiving orthodontic treatment that involves intrusion of teeth; upper incisors, lower incisors or posterior teeth, with no restriction on the type of overall associated malocclusion.

\section{Exclusion Criteria}

-Case control, review article, prospective studies, and studies that have no control group.

-Animal studies.

-Any study before 2000 .

- Studies that did not factor out the vertical growth component which continues up into the mid-twenties.

\section{Intervention}

The use of temporary anchorage devices (TADs) as a method for orthodontic intrusion compared to any alternative intrusion devices or techniques.

\section{Outcomes}

\section{Primary Outcome}

Amount of intrusion (measured using cephalometric X-ray from upper incisors to palatal plane and overbite in millimeters).

\section{Secondary Outcome}

- Adverse effect on roots (such as external root resorption)

- Effect on periodontal supporting tissues.

- Effect on posterior teeth.

\section{Search Strategy}

A literature search was conducted to identify all studies that measured the amount of orthodontic intrusion using TADs in comparison to different orthodontic techniques. An electronic search was conducted with no language restrictions on publication dates ranging from January 2000 as the beginning of the 21st century and the new era of implant design to June 2019. Cochrane, MEDLINE by way of PubMed, Lilacs, ScienceDirect, Scopus, and Clinicaltraila. Gov were the databases searched. The reference lists of the selected articles were also searched for other applicable publications.

Terms used were the following: "mini-implants" OR "mini-screw" OR "TAD" AND "orthodontic intrusion." The terms were chosen generally to eliminate any possibility of missing a comparison study with other techniques which might not be included in the search term.

\section{Types of Studies}

All randomized controlled trials (RCTs), controlled clinical trials (CCTs), and prospective studies that compared the use of TADs to alternative intrusion devices and techniques.

\section{Selection Method}

Initial eligibility was determined by reading the title and the abstract of each article identified by the search and then full text articles were retrieved from the selected abstracts/titles. Two reviewers were assigned to screen the articles after removal of the duplicate records in order to retrieve the full articles for final eligibility. Discussion was held to resolve any discrepancies. All the articles that seemed to fulfill the inclusion criteria based on a reading of their abstracts were attained if one of the reviewers deemed it possibly relevant. The final selection was independently and in duplicate made by four reviewers after reading the full articles. The kappa test was utilized for measuring inter-examiner agreement. References of the selected articles were also searched for any potentially missed publications.

\section{Data Mining}

Language, year of publication, intervention methods, sample size, age of the subjects, and teeth being intruded were all documented in a table.

\section{Quality Assessment}

The quality of the studies was evaluated by using the methodological score for clinical trials developed by 
Lagravère et al. ${ }^{4}$ The elements of the assessment are shown in Table 1.

\section{Results}

\section{Literature Search}

The search strategy using the keywords shown in Table 2 provided 3942 results. After removing the duplicate records, 70 articles remained and were screened based on the inclusion criteria and 14 articles qualified, after reading the abstracts for the final analysis. Twelve studies were then excluded because of the age of the participants (Table 3). ${ }^{2,5-15}$ The excluded studies assessed growth based on either the hand-wrist or the cervical vertebral maturation (CVM) radiograph for determining the end of the growth phase. However, the vertical growth pattern is well known to continue after the adolescent growth spurt and well into mid-adulthood in both males and females, and those studies did not factor out this component. ${ }^{16}$ This resulted in two studies that fully met the inclusion criteria and were finally included in this review. ${ }^{17,18}$ The review details and selection process are given in Figure 1 as described in the PRISMA statement. ${ }^{19}$ The inter-examiner agreement (kappa test) was 0.833 following the initial eligibility assessment and 1.000 after the reading of the full articles.

Table I Methodological Scores of Clinical Trials ${ }^{4}$

\begin{tabular}{|c|c|}
\hline Study design & $\begin{array}{l}\text { - Objective: Objective clearly formulated }(\sqrt{ }) \\
\text { - Population: Described }(\sqrt{ }) \\
\text { - Selection criteria: Clearly described }(\sqrt{ }) \text {, adequate } \\
(\sqrt{ }) \\
\text { - Sample size: Considered adequate }(\sqrt{ }) \text {, estimated } \\
\text { before collection of data }(\sqrt{ }) \\
\text { - Baseline characteristics: Similar baseline charac- } \\
\text { teristics }(\sqrt{ }) \\
\text { - Timing: Prospective }(\sqrt{ }) \\
\text { - Randomization: Stated }(\sqrt{ })\end{array}$ \\
\hline $\begin{array}{l}\text { Study } \\
\text { measurement }\end{array}$ & $\begin{array}{l}\text { - Measurement methods: Appropriate to the objec- } \\
\text { tive }(\sqrt{ }) \\
\text { - Blind Measurements: Examiner }(\sqrt{ }) \text {, statistician }(\sqrt{ }) \\
\text { - Reliability: Described }(\sqrt{ }) \text {, adequate level of agree- } \\
\text { ment }(\sqrt{ })\end{array}$ \\
\hline $\begin{array}{l}\text { Statistical } \\
\text { analysis }\end{array}$ & $\begin{array}{l}\text { - Dropouts: Dropouts included in the analysis }(\sqrt{ }) \\
\text { - Statistical analysis: Appropriate for data }(\sqrt{ }) \text {, com- } \\
\text { bined subgroup analysis }(\sqrt{ }) \\
\text { - Confounders: Confounders included in the analy- } \\
\text { sis }(\sqrt{ }) \\
\text { - Statistical significant level: } P \text { value stated }(\sqrt{ }) \text {, con- } \\
\text { fidence intervals }(\sqrt{ })\end{array}$ \\
\hline
\end{tabular}

Notes: $\sqrt{ }$, Fully fulfilled the methodological criteria; maximum number of checks $=20$. Adapted from Lagravère MO, Major PW, Flores-Mir C. Long-term skeletal changes with rapid maxillary expansion: a systematic review. Angle Orthod. 390 2005;75(6): 1046-1052; permission conveyed through Copyright Clearance Center,Inc. ${ }^{4}$

\section{Characteristics of Included Studies}

This systematic review search strategy had no language restrictions. As a result, a randomized clinical trial by $\mathrm{Ma}$ Dan et $\mathrm{al}^{17}$ in the Chinese language was included and translated by the Saudi-Chinese Institute in Khobar, Saudi Arabia. The other included study by Deguchi T. et al was a prospective clinical trial in English. ${ }^{18}$

The first study compared the use of the mini-screw versus the utility arch, while the other one compared the efficacy of implants versus the use of J-hook headgear in intruding the maxillary incisor teeth.

A summary of the sample sizes, the type of TAD and the conventional technique used (utility arch and J-hook headgear) as well as the radiograph in the included studies are given in Table 4. Quality assessment criteria from Lagravère et al were applied to each article and the final scores for each are presented in Table $5 .^{4}$

\section{Intervention Results Comparison of Intrusion Between Mini-Screws and Conventional Methods (Utility Arch and J-Hook Headgear)}

The two studies that fulfilled the inclusion criteria are summarized in Table 6.

\section{Rate of Activation}

A monthly activation was the protocol used in the two studies.

\section{Technique Description}

Both studies used a similar size of TAD, ranging from 1.5 to $1.6 \mathrm{~mm}$ in diameter, with a length of 6 to $8 \mathrm{~mm}$, but using different applied forces. The Ma Dan et al study applied $50 \mathrm{~g}$ of force for the mini-screw group, ${ }^{17}$ while Deguchi T. et al applied a range of 80 to $120 \mathrm{~g}$ of intrusion force for the implant group. ${ }^{18}$

Both studies used $100 \mathrm{~g}$ of force for the conventional groups. The Deguchi ${ }^{18}$ et al study, however, included the condition of wearing the headgear for more than 7 hours a day.

\section{Area of Activation}

Ma Dan et $\mathrm{al}^{17}$ used the distal end of the lateral incisor region as the preferred area of intervention, while Deguchi $T$. et al $^{18}$ mentioned using the premaxillary region as the placement area of the TAD without further specification.

\section{Adverse Effect}

The measurements in the Ma Dan et al study showed adverse effects on molar movement measured from the 
Table 2 Search Results of the Different Databases

\begin{tabular}{|c|c|c|c|}
\hline Database & Keywords & Results & Selected \\
\hline Pubmed/MEDLINE & $\begin{array}{l}\text { I- Intrusion AND mini-screw OR mini-implants OR TAD OR micro-implants. } \\
\text { 2- Intrusion AND implant anchorage OR absolute anchorage. } \\
\text { 3- Effects of miniscrew on intrusion. } \\
\text { Species= humans } \\
\text { Date of Publication= 2000-2019 Article types= RCT } \\
\text { Controlled clinical trial, prospective studies }\end{array}$ & 1860 & 45 \\
\hline Cochrane & $\begin{array}{l}\text { I- Intrusion AND mini-screw OR mini-implants OR TAD OR micro-implants } \\
\text { 2- Intrusion AND implant anchorage OR absolute anchorage. } \\
\text { 3- Effects of mini-screw on intrusion. } \\
\text { Year of publication=2000-2019 }\end{array}$ & 516 & 7 \\
\hline Lilacs & $\begin{array}{l}\text { I- Intrusion AND mini-screw OR mini-implants OR TAD OR micro-implants } \\
\text { 2- Intrusion AND implant anchorage OR absolute anchorage. } \\
\text { 3- Effects of mini-screw on intrusion. } \\
\text { Age=Adults Year of publication }=2000-2019\end{array}$ & 105 & 0 \\
\hline Scopus & $\begin{array}{l}\text { I- Intrusion AND mini-screw OR mini-implants OR TAD OR micro-implants. } \\
\text { 2- Intrusion AND implant anchorage OR absolute anchorage. } \\
\text { 3- Effects of mini-screw on intrusion. } \\
\text { Date of publication= } 2000-2019 \text { Subject area= dentistry }\end{array}$ & 215 & 6 \\
\hline ScienceDirect & $\begin{array}{l}\text { I- Intrusion AND mini-screw OR mini-implants OR TAD OR micro-implants. } \\
\text { 2- Intrusion AND implant anchorage OR absolute anchorage. } \\
\text { 3- Effects of mini-screw on intrusion. } \\
\text { Year=2000-2019 } \\
\text { Type: Review, research publications } \\
\text { Journals= orthodontics-related }\end{array}$ & 1246 & 12 \\
\hline \multicolumn{2}{|l|}{ Total } & 3942 & 70 \\
\hline
\end{tabular}

Table 3 Studies That Fulfilled Initial Selection Criteria but Were Later Rejected

\begin{tabular}{|l|l|}
\hline Authors & Reason(s) for Rejection \\
\hline Polat-Özsoy, Ö. et al & Age group does not fit the inclusion criteria \\
Senıșik, N. E. et al & \\
Aydoğdu, E. Özsoy Ö. P. & Age group does not fit the inclusion criteria \\
Kumar, C. P. et al & Age group does not fit the inclusion criteria \\
Gupta N. et al & Age group does not fit the inclusion criteria \\
Jain RK et al & Age group does not fit the inclusion criteria \\
Kahraman F et al & Age group does not fit the inclusion criteria \\
Gürlen SÖ et al & Age group does not fit the inclusion criteria \\
Salim MA, Mousa Sh & Age group does not fit the inclusion criteria \\
Deguchi Tet al & Age group does not fit the inclusion criteria \\
Bhat et al & Age group does not fit the inclusion criteria \\
Arora A et al ${ }^{15}$ & Age group does not fit the inclusion criteria \\
\hline
\end{tabular}

center of resistance and relative to the palatal plane in the conventional groups, which translates to $f$ of molars. The other study showed no significant effect on the molars between the two groups.

\section{Amount of Intrusion}

The amount of intrusion obtained by Ma Dan et $\mathrm{al}^{17}$ in the TAD group was $3.4 \mathrm{~mm} \pm 1.17 \mathrm{~mm}$ and $2.95 \mathrm{~mm} \pm$ $0.78 \mathrm{~mm}$ in the utility arch group. An average of $3.6 \mathrm{~mm}$ 


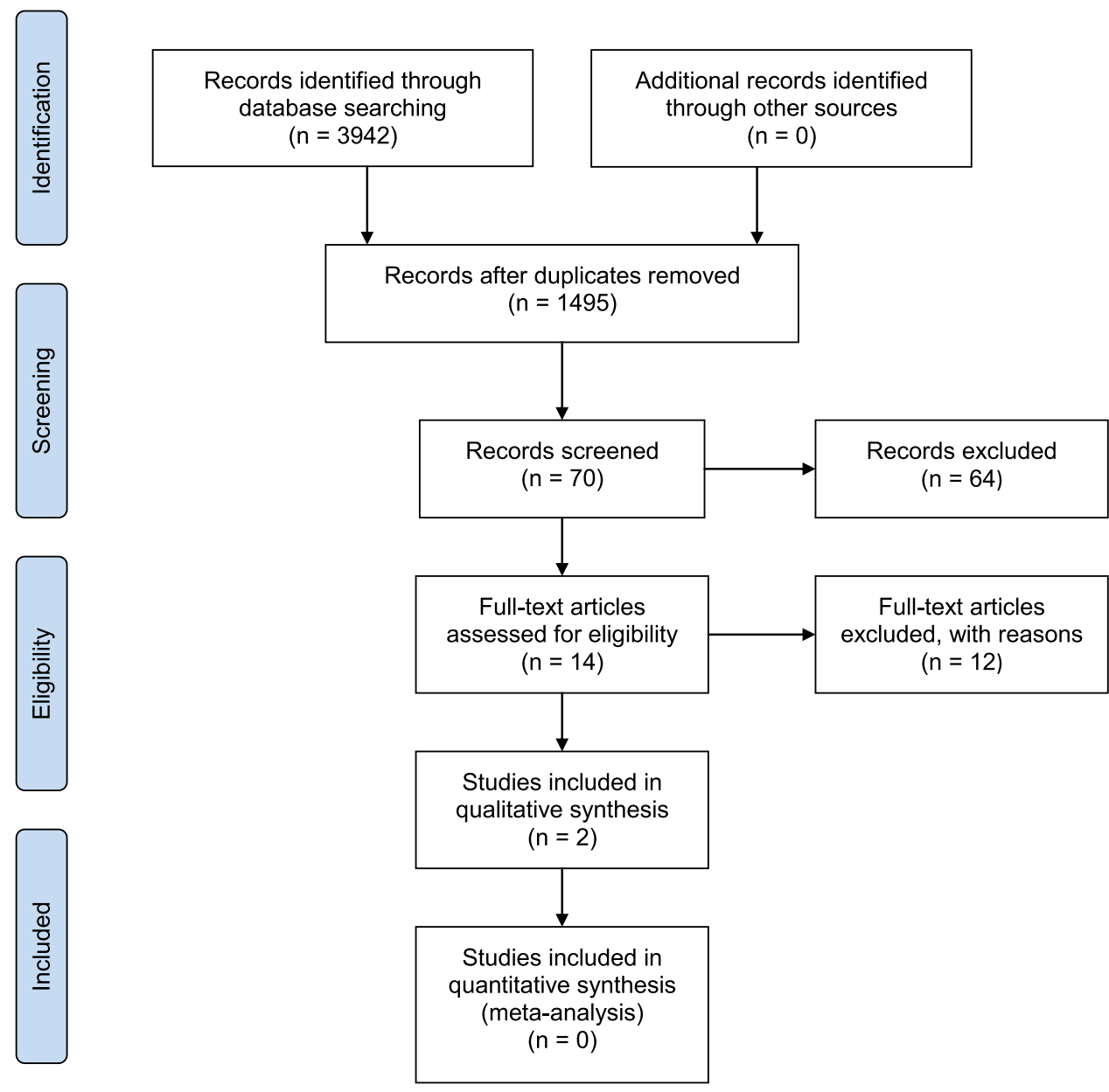

Figure I PRISMA flow diagram of the selection process.

Notes: Adapted from Moher D, Liberati A, Tetzlaff J, Altman DG, The PRISMA Group (2009). Preferred Reporting Items for Systematic Reviews and Meta-Analyses: The PRISMA Statement. PLoS Med 6(7): el $000097 .^{19}$

and a maximum of $5 \mathrm{~mm}$ of intrusion were obtained in the Deguchi et al study in the TAD group. ${ }^{18}$ This was compared to the J-hook headgear group where only an average of $1.1 \mathrm{~mm}$ and a maximum of $3 \mathrm{~mm}$ were obtained. The incisor edge to palatal plane distance was used as a reference point in both studies.

A statistically significant difference was found in both studies in terms of the reduction of the overbite as well as the distance from the upper lip to the maxillary incisors in the TAD groups in comparison to the conventional groups The Deguchi $T$. et al study further found a significant reduction in the maxillary incisal edge to palatal plane measurement. ${ }^{18}$

\section{Technique Safety}

There were no comparable side effects found to be measured between the two studies, but the effect of intrusion on periodontal health was assessed in the MA Dan et al

Table 4 Studies Included After All Review Stages

\begin{tabular}{|c|c|c|c|c|}
\hline Authors & Collective Sample & TADs group & $\begin{array}{l}\text { Conventional Technique } \\
\text { Group }\end{array}$ & Radiograph \\
\hline MA Dan et al ${ }^{17}$ & $\begin{array}{l}20 \text { ( } 8 \text { male and } 12 \\
\text { female) }\end{array}$ & Mini-screw: 10 & Utility arch: 10 & $\begin{array}{l}\text { Lateral cephalometric and periapical } \\
\text { radiographs }\end{array}$ \\
\hline $\begin{array}{l}\text { Deguchi } \\
\text { T. et } \text { al }^{18}\end{array}$ & $\begin{array}{l}18 \text { (16 female and } 2 \\
\text { male) }\end{array}$ & $\begin{array}{l}\text { Implant group: } \\
8\end{array}$ & J-HG group: 10 & $\begin{array}{l}\text { Lateral cephalometric and periapical } \\
\text { radiographs }\end{array}$ \\
\hline
\end{tabular}


Table 5 Methodological Score of the Selected Articles

\begin{tabular}{|l|l|l|l|l|l|l|l|l|l|l|l|l|l|l|l|l|}
\hline Articles & A & B & C & D & E & F & G & H & I & J & K & L & M & N & Total No. of Checks & \% of the Total \\
\hline Ma Dan et al $^{17}$ & $\sqrt{ }$ & $\sqrt{ }$ & $\sqrt{ } \sqrt{ }$ & - & $\sqrt{ }$ & $\sqrt{ }$ & $\sqrt{ }$ & $\sqrt{ }$ & -- & -- & - & $\sqrt{ } \sqrt{ }$ & $\sqrt{ }$ & $\sqrt{ }-$ & $12 / 20$ & 60 \\
Deguchi et al $^{18}$ & $\sqrt{ }$ & $\sqrt{ }$ & $\sqrt{ } \sqrt{ }$ & - & $\sqrt{ }$ & $\sqrt{ }$ & - & $\sqrt{ }$ & -- & -- & - & $\sqrt{ }$ & $\sqrt{ }$ & $\sqrt{ }-$ & $I 1 / 20$ & 55 \\
\hline
\end{tabular}

Notes: $\sqrt{ }$, Fully fulfilled the methodological criteria ( $I$ check point). $\sqrt{ }$, Fully fulfilled the methodological criteria $(2$ check points). $\neq$, Partially fulfilled the methodological criteria ( 0.5 check point). -, Did not fulfill the methodological criteria ( 0 check point); - -, Did not fulfill the methodological criteria $(0$ check point). Criteria are given in Table I.

study. ${ }^{17}$ The study found no significant difference in all measured variables before and after the treatment while using TAD compared to the conventional orthodontic technique. The other study assessed root resorption and found significantly more external apical root resorption in the conventional method group (the utility arch group). ${ }^{18}$

Meta-analysis could not be conducted of the complied data because of the inconsistency of the variables that were assessed.

\section{Discussion}

\section{Intrusion is a Frequent Treatment Modality Used to Achieve Better Aesthetic and/or Functional Results}

Although two recent systematic reviews were recently conducted to evaluate the effectiveness of TADs for the intrusion of upper incisors, our review is considered as the first one to evaluate the effectiveness of bone anchorage devices; TADs or miniplates for orthodontic intrusion of maxillary incisors, mandibular incisors, and maxillary molars, as compared to conventional methods of intrusion in adults. Our study included only two studies, while the previous studies included 6 to 7 studies in their reviews, although their search was limited to TADs intrusion of incisors. ${ }^{20}$ This is attributed to the different age limit used in our study (above 18 years), which was different than that used in the other two reviews (above 14 or 15 years). The reason for that was to exclude the effect of vertical growth on the actual intrusion of incisors, which we believe might give false reading of the amount of intrusion.

From the final two studies that fully met the inclusion criteria, it is seen that there is a significant difference in terms of intrusion using TAD versus other orthodontic techniques which denied the null hypothesis. The difference is evident specifically in treating deep bite cases in adult non-growing patients to ensure that vertical growth is mostly completed, as late vertical growth continues after the growth spurt period. ${ }^{21}$
Both studies found that the amount of intrusion resulting from using TAD was greater compared to conventional techniques due to the flexibility of choosing the location of the mini-screw relative to the center of resistance, and the ability to control and reduce the undesirable side effects.

The two included studies had inadequate sample sizes, which make their results difficult to generalize. Furthermore, the gender distribution greatly favored female patients in both studies which could generate a gender bias in the results. However, in Afrashtehfar $\mathrm{K}$. et al meta-analysis based on non-randomized clinical studies, it was concluded that there was no significant difference observed between male and female patients as a success factor of orthodontic treatment when using miniscrew implant. ${ }^{22}$

Another limitation is that all patients included in the sample were treated with four premolar extraction which makes the separation of the results of intrusion and retraction impossible, although it was mentioned that the measurement of intrusion was taken before they started retraction.

In the Deguchi $T$ et al study, most of the force applied in the TAD group was vertical, which favors the intended intrusion movement. With the J-hook headgear, however, more horizontal force was distributed in comparison to the TAD group. Similarly, less intrusion was found in the Ma Dan et al study using the conventional utility arch technique. This is mostly attributed to the fact that this technique produces relatively more extrusive effect on molars and mesialization than intrusive movement on anteriors.

Although the use of TAD favors more control of incisor inclination and should result in less flaring of upper anterior teeth, the Deguchi et al study showed different results with less incisor flaring in the J-HG group compared to the TAD group, probably due to more horizontal force distribution than vertical using J-HG compared to the TAD group. The other possible explanation is the positioning of the implant more labially from the center of resistance in the TAD group. 
Table 6 Summary of the Included Studies

\begin{tabular}{|c|c|c|}
\hline & Ma Dan et al ${ }^{17}$ & Deguchi Tet al ${ }^{18}$ \\
\hline Study design & Randomized clinical trial & Prospective study \\
\hline Language & Chinese & English \\
\hline Sample size & $\begin{array}{l}20 \text { adults( } 12 \text { female and } 8 \text { male) } \\
\text { Mini-screw: } 10 \\
\text { Utility arch: } 10\end{array}$ & $\begin{array}{l}\text { I8 (I6 female and } 2 \text { male) } \\
\text { Implant group: } 8 \\
\text { J-HG group: } 10\end{array}$ \\
\hline Mean Age (years) & $\begin{array}{l}\text { Mini-screw group: } 22.6 \\
\text { Utility arch group: } 21.8\end{array}$ & $\begin{array}{l}\text { J-HG group: } 20.7 \\
\text { Implant group: } 21.5\end{array}$ \\
\hline Percent of female patients in group & $60 \%$ & $89 \%$ \\
\hline Intruded teeth & Maxillary incisors & Maxillary incisors \\
\hline Technique used in TAD & Direct & Direct \\
\hline Force duration & $\begin{array}{l}\text { Mini-screw: intermittent } \\
\text { Utility arch: continuous }\end{array}$ & $\begin{array}{l}\text { Mini-screw: transient } \\
\text { J-HG: intermittent }\end{array}$ \\
\hline Method of activation & Not mentioned & $\begin{array}{l}\text { J-HG: edgewise appliance with stainless steel wire } \\
\text { Mini-screw: ligature wire }\end{array}$ \\
\hline Alignment and leveling & Performed & Not mentioned \\
\hline TAD size & $\begin{array}{l}\text { Diameter: } 1.6 \mathrm{~mm} \\
\text { Length: } 8 \mathrm{~mm}\end{array}$ & $\begin{array}{l}\text { Diameter: } 1.5 \mathrm{~mm} \\
\text { Length: } 6 \mathrm{~mm}\end{array}$ \\
\hline Applied force & $\begin{array}{l}\text { Mini-screw: } 50 \mathrm{~g} \\
\text { Utility arch: } 100 \mathrm{~g}\end{array}$ & $\begin{array}{l}\text { Mini-screw: } 80 \text { to } 120 \mathrm{~g} \\
\text { J-HG group: } 100 \mathrm{~g} \text { per side for more than } 7 \text { hours per day. }\end{array}$ \\
\hline Location of TAD & Between the maxillary lateral and canine & Premaxillary region between the central and lateral incisors \\
\hline Treatment duration & $\begin{array}{l}\text { Mini-screw: } 4 \text { to } 9 \text { months } \\
\text { Utility arch: } 4 \text { to } 10 \text { months }\end{array}$ & 7 months \\
\hline Rate of activation & Monthly & Monthly \\
\hline Loading & After 2 weeks & After I month of healing \\
\hline $\begin{array}{l}\text { Technique safety (root resorption, } \\
\text { periodontal problems) }\end{array}$ & $\begin{array}{l}\text { Root resorption: Not assessed } \\
\text { Periodontal tissues: No significant difference in periodontal } \\
\text { supporting tissues between the } 2 \text { groups }\end{array}$ & $\begin{array}{l}\text { Root resorption: significantly more external apical root } \\
\text { resorption in the headgear group } \\
\text { Periodontal tissues: Not assessed }\end{array}$ \\
\hline Intrusion calculation method & $\begin{array}{l}\text { Comparing pre- and post-intrusion } \\
\text { I) Cephalometric X-ray observing: UI-PP \& UI-Stm } \\
\text { 2) Measuring overbite in } \mathrm{mm}\end{array}$ & $\begin{array}{l}\text { Comparing pre- and post-intrusion } \\
\text { I) Cephalometric X-ray observing: UI-PP \& UI-SN \& UI- } \\
\text { upper lip } \\
\text { 2) Measuring overbite in } \mathrm{mm}\end{array}$ \\
\hline $\begin{array}{l}\text { Amount of obtained intrusion } \\
\text { calculated in both studies }\end{array}$ & $\begin{array}{l}\text { Mini-screw group: } \\
\text { UI-PP }=3.4 \pm 1.17 \mathrm{~mm} \\
\text { Overbite }=-4.1 \pm 0.88 \\
\text { Utility arch group: } \\
\text { UI-PP }=2.95 \pm 0.78 \mathrm{~mm} \\
\text { Overbite }=-3.76 \pm 0.78\end{array}$ & $\begin{array}{l}\text { Mini-screw group: } \\
\text { UI-PP }=3.6 \pm 1.7 \\
\text { Overbite }=-4.5 \pm 1.7 \\
\text { J-HG group: } \\
\text { UI-PP }=-1.1 \pm 1.6 \\
\text { Overbite }=-3.4 \pm 1.0\end{array}$ \\
\hline Classification of malocclusion & Class I malocclusion with deep OB & Not specified (deep bite malocclusion) \\
\hline Deep bite selection criteria & Patients with incompetent lip, class III deep bite & $\begin{array}{l}\text { Patients with excessive display of maxillary incisors and high } \\
\text { mandibular plane angle (gummy smile) }\end{array}$ \\
\hline
\end{tabular}


On the other hand, Ma Dan et al found no change in the form of flaring as measured by U1-SN in the implant group, while significant difference was found in the utility arch group. These findings reflect better control in their TAD group compared to the utility arch group. This highlights the importance of careful planning and choosing the method of intrusion in relation to the center of resistance, as it might affect the final result. This is in agreement with results from the Dake M. L. and Sinclair P. M. study as they demonstrated more incisor flaring using the utility arch due to the fact that the arch is positioned labial to the center of resistance. ${ }^{23}$ In contrast, Alqabandi et al found that there is retroclination when using the utility arch, which they attributed to cinching back the wire distal to the molars. ${ }^{24}$

The distance from the maxillary incisal edge to the palatal plane (U1-PP) measurement as a reference point of intrusion was used in both included studies. Ma Dan et al also used a soft tissue reference (the U1-Stm). However, the distance from the incisal edge to the PP might not be the ideal reference choice when performing intrusion and retraction which were performed in both included studies, as it can result in different values depending on the position of the incisal edge. Instead, the incisor central can be a more accurate reference, referring to a point on the longitudinal axis of the tooth that is independent of any inclination changes. ${ }^{6}$ Not only that, both studies used two-dimensional radiograph, which might question the outcome of the studies.

Both studies that were finally included in this review were done on patients of Asian ethnicity which may have introduced bias into the results. It has been reported in the literature that racial variations in soft tissue-to-hard tissue movement ratios exist in tissue response. ${ }^{25}$ As a result, the generalization of our conclusion might not be applicable to different ethnicities.

Our search strategy was not limited to evaluating the intrusion on a specific area of dentition, and only maxillary anterior intrusion was assessed in the studies included in this review. Julia Ng et al reported that there is greater mandibular incisor intrusion than maxillary incisor intrusion in adult patients, although the bone in the mandible is more dense in the anterior segment of the arch. ${ }^{26}$ No studies were found fulfilling the inclusion criteria on the intrusion of posterior teeth using TAD compared to conventional methods.

Both studies assessed different biological side effects of intrusion. Ma Dan et $\mathrm{al}^{17}$ reported no significant difference in probing depth and width of the keratinized gingiva between the TAD and utility arch groups, this is in agreement with Bayani et $\mathrm{al}^{27}$ that found no significant change of probing depth during intrusion with miniscrew. In fact, a clinical attachment gain and shortening of clinical crown height has been observed.

Deguchi et $\mathrm{al}^{18}$ evaluated the amount of external root resorption, which turned out to be more significant in the J-hook headgear group. The reason for this might be due to the jiggling effect on the tooth depending on the patient's cooperation using the J-HG which is a known factor for external root resorption, while the transient force generated by the ligature wire in the implant group could be the reason for the significantly less root resorption ${ }^{18}$ in the TAD group, another important factor is that using a more controlled and less force in the TAD group is more likely a considerable factor. This is in agreement with Polat-Özsoy et al. ${ }^{2}$ Kuroda and Tanaka et $\mathrm{al}^{28}$ and Kravitz et $\mathrm{al}^{29}$ who reported no sign of root resorption using TADs for intrusion, although the last two studies were done on molars.

Twelve studies that met the initial inclusion criteria were rejected after reading the full articles based on their assessment of growth. ${ }^{2,5-15}$ All of them considered the sample to be adults based on hand-wrist or the cervical vertebral maturation (CVM) radiograph. We excluded these studies on the basis that they did not factor out the vertical growth component which continues up into the mid-twenties. ${ }^{21}$

\section{Conclusion}

There is low to medium evidence on the effectiveness of TADs as a method of intrusion of upper anterior teeth compared to other alternative techniques used.

There is no evidence on the effectiveness of TADs as a method of intrusion of lower anterior teeth or posterior teeth, compared to other alternative techniques used.

Due to the low number of the included studies, our conclusions should be interpreted with caution. Future high quality prospective randomized clinical trials are required.

\section{Disclosure}

The authors report no conflicts of interest for this work.

\section{References}

1. Schätzle M, Männchen R, Zwahlen M, Lang NP. Survival and failure rates of orthodontic temporary anchorage devices: a systematic review. Clin Oral Implants Res. 2009;20(12):1315-1319.

2. Polat-Özsoy Ö, Arman-Özçırpıcı A, Veziroğlu F, Çetinşahin A. Comparison of the intrusive effects of mini-screws and utility arches. Am J Orthod Dentofacial Orthop. 2011;139(4):526-532.

3. Mizrahi E, Mizrahi B. Mini-screw implants (temporary anchorage devices): orthodontic and pre-prosthetic applications. J Orthod. 2007;34(2):80-94. 
4. Lagravère MO, Major PW, Flores-Mir C. Long-term skeletal changes with rapid maxillary expansion: a systematic review. Angle Orthod. 2005;75(6):1046-1052.

5. Senışık NE, Türkkahraman H. Treatment effects of intrusion arches and mini implant systems in deep bite patients. Am J Orthod Dentofacial Orthop. 2012;141(6):723-733.

6. Aydoğdu E, Özsoy ÖP. Effects of mandibular incisor intrusion obtained using a conventional utility arch vs bone anchorage. Angle Orthod. 2011;81(5):767-775.

7. Kumar P, Datana S, Londhe SM, Kadu A. Rate of intrusion of maxillary incisors in Class II Div 1 malocclusion using skeletal anchorage device and Connecticut intrusion arch. Med J Armed Forces India. 2017;73(1):65-73. doi:10.1016/j.mjafi.2015.10.006

8. Gupta N, Tripathi T, Rai P, Kanase A. A comparative evaluation of bite opening by temporary anchorage devices and Connecticut intrusion arch: an in vivo study. Int J Orthod Rehabil. 2017;8:129-135.

9. Jain RK, Kumar SP, Manjula WS. Comparison of intrusion effects on maxillary incisors among mini implant anchorage, J-hook headgear and utility arch. J Clin Diagn Res. 2014;8:21-24.

10. Kahraman F, Kilic N, Dagsuyu İM. Farklı Kesici İntrüzyon Mekaniklerinin Daimi Üst Birinci Molar Dişlere Etkilerinin Üç Boyutlu Olarak Değerlendirilmesi. Cumhuriyet Dental J. 2017;20:113-121.

11. SÖ G, Aras I. Comparison of the treatment effects of two intrusive mechanics: connecticut intrusion arch and mini-implant. Turkiye Klinikleri Dishekimligi Bilimleri Dergisi. 2016;22:195-201.

12. Salim MA, Mousa S. Treatment of deep bite by using mini implants in comparison to Conventional orthodontic technique. Ain $D S J$. 2015;XVII:1-6.

13. Kurosaka T, Oikawa H, Kuroda H. Comparison of orthodontic treatment outcomes in adults with skeletal open bite between conventional edgewise treatment and implant-anchored orthodontics. Am j Orthodontics Dentofacial. 2011;139:S60.

14. Bhat M, Madhur V. Evaluation of apical root resorption in orthodontic patients with maxillary anterior intrusion using utility arches and mini screws: A comparative clinical trial. APOS Trends Orthodontics. 2014;4:3. doi:10.4103/2321-1407.125742

15. Arora A, Garg S, Reddy R. Comparison of vertical parameters in correction of deep bite using an implant and utility intrusion arch. IOSR J Dental Med Sci. 2016;15:92-95.

16. Proffit WR, Fields HW, Sarver DM. Contemporary Orthodontics. 5th ed. St. Louis, Mo, USA: Mosby; 2013.
17. Dan M, Xu-xia W, Shu-mei J, et al. Comparison of two treatment method for maxillary incisor intrusion. Shanghai J Stomatology. 2013;02:206-209.

18. Deguchi T, Murakami T, Kuroda S, Yabuuchi T, Kamioka H, TakanoYamamoto T. Comparison of the intrusion effect on the maxillary incisors between implant anchorage and J-hook headgear. Am J Orthod Dentofacial Orthop. 2008;133(5):654-660.

19. Liberati A, Altman DG, Tetzlaff J, et al. The PRISMA statement for reporting systematic reviews and meta-analyses of studies that evaluate healthcare interventions: explanation and elaboration. BMJ. 2009;399:b2700.

20. Sosly R, Mohammed H, Rizk MZ, Jamous E, Qaisi AG, Bearn DR. Effectiveness of miniscrew-supported maxillary incisor intrusion in deep-bite correction: A systematic review and meta-analysis. Angle Orthod. 2020;90(2):291-304. doi:10.2319/061119-400.1

21. Sharma P, Arora A, Valiathan A. Age changes of jaws and soft tissue profile. Review article. Sci World J. 2014;301501.

22. Afrashtehfar K. Patient and miniscrew implant factors influence the success of orthodontic miniscrew implants. Evid Based Dent. 2016;17:109-110

23. Dake M, Sinclair P. Comparison of the Ricketts and Tweed type arch leveling technique. Am J Orthod Dentofacial Orthop. 1989;95:72-78.

24. Alqabandi A, Sadowsky C, Selke T. A comparison of continuous archwire and utility arch for leveling of the curve of Spee. World J Orthod. 2002;3:159-165.

25. Kolokitha OE, Chatzistavrou E. Factors influencing the accuracy of cephalometric prediction of soft tissue profile changes following orthognathic surgery. J Maxillofac Oral Surg. 2012;11(1):82-90.

26. Ng J, Major PW, Heo G, Flores-Mir C. True incisor intrusion attained during orthodontic treatment: a systematic review and meta-analysis. Am J Orthod Dentofacial Orthop. 2005;128(2):212-219.

27. Bayani S, Heravi F, Radvar M, Anbiaee N, Madani AS. Periodontal changes following molar intrusion with miniscrews. Dent Res $J$ (Isfahan). 2015;12(4):379-385. doi:10.4103/1735-3327.161462

28. Kuroda S, Tanaka E. Risks and complications of miniscrew anchorage in clinical orthodontics. Japanese Dental Sci Rev. 2014;50 (4):79-85.

29. Kravitz ND, Kusnoto B, Tsay TP, Hohlt WF. The use of temporary anchorage devices for molar intrusion. J Am Dent Assoc. 2007;138 (1):56-64.
Clinical, Cosmetic and Investigational Dentistry

\section{Publish your work in this journal}

Clinical, Cosmetic and Investigational Dentistry is an international, peer-reviewed, open access, online journal focusing on the latest clinical and experimental research in dentistry with specific emphasis on cosmetic interventions. Innovative developments in denta materials, techniques and devices that improve outcomes and patient satisfaction and preference will be highlighted. The manuscript management system is completely online and includes a very quick and fair peer-review system, which is all easy to use. Visit http://www.dovepress.com/testimonials.php to read real quotes from published authors. 